\title{
ORIGINAL ARTICLE \\ Genetic mapping of two components of reproductive isolation between two sibling species of moths, Ostrinia nubilalis and 0 . scapulalis
}

\author{
Réjane Streiff ${ }^{1}$, Brigitte Courtois ${ }^{2}$, Serge Meusnier ${ }^{1}$ and Denis Bourguet ${ }^{1}$ \\ We report the quantitative trait loci (QTL) mapping of reproductive isolation traits between Ostrinia nubilalis (the European corn \\ borer) and its sibling species $O$. scapulalis (the Adzuki bean borer), focusing on two traits: mating isolation (mi) and pheromone \\ production (Pher). Four genetic maps were generated from two backcross families, with two maps (one chromosomal map and \\ one linkage map) per backcross. We located 165-323 AFLP markers on these four maps, resulting in the identification of \\ 27-31 linkage groups, depending on the map considered. No-choice mating experiments with the offspring of each backcross \\ led to the detection of at least two QTLs for $m i$ in different linkage groups. QTLs underlying Pher were located in a third linkage \\ group. The Z heterochromosome was identified by a specific marker (Tpi) and did not carry any of these QTLs. Finally, we \\ considered the global divergence between the two sibling species, distortions of segregation throughout the genome, and the \\ location and effect of $m i$ and Pher QTLs in light of the known candidate genes for reproductive isolation within the genus \\ Ostrinia and, more broadly, in phytophagous insects.
}

Heredity (2014) 112, 370-381; doi:10.1038/hdy.2013.113; published online 13 November 2013

Keywords: QTL mapping; European corn borer; Adzuki bean borer; Ostrinia; mating isolation; ecological speciation

\section{INTRODUCTION}

In animals, algae and plants, many species initially classified as generalists have proved to be complexes of different taxa-be it varieties, races or sibling species-displaying little or no phenotypic differentiation, but each specializing in a particular habitat (Leliaert et al., 2009; Speybroeck et al., 2010; Keller and Seehausen, 2012). In particular, phytophagous insect species previously considered to be polyphagous are frequently found to be mixtures of genetically differentiated, specialist taxa, each feeding on a restricted range of host plants (Berlocher and Feder, 2002; Drès and Mallet, 2002; Dyer et al., 2007; Feder and Nosil, 2010; Matsubayashi et al., 2010). These specialized taxa display a recurrent pattern of host-plant associations, together with partial or complete reproductive isolation in sympatry. This has led to claim that adaptation to different host plants may be a major source of speciation in insects (Matsubayashi et al., 2010).

For phytophagous species living in sympatry and specializing on different host plants, the crucial issue is the establishment and maintenance of reproductive isolation. At the postzygotic level, host adaptation may cause reduced hybrid viability and directly induce a reproductive isolation even in the absence of a mate preference. At the prezygotic level, various mechanisms have been described, from direct effects of host-plant phenology, leading to a shift in reproductive season in the host-affiliated insect (Wood and Keese, 1990; Pratt, 1994; Feder and Filchak, 1999), to 'magic' traits (or genes) involved in both adaptation and mating success. A striking example is provided by wing color patterns in Heliconius, with variations of these patterns being involved in both mating preference and mimicry defense strategy (Jiggins, 2008; Servedio et al., 2011). Host adaptation and mate preference are thus both putative components of reproductive isolation while it has been suggested that the genetic architecture of reproductive isolation and adaptive traits is a major element in this adaptation - isolation link (Rundle and Nosil, 2005). Indeed, the probability of speciation is increased by the existence of tight linkage (or even pleiotropy) between genes conferring host adaptation and genes involved in reproductive isolation, and by these genes being few in number (Hawthorne and Via, 2001; Berlocher and Feder, 2002).

Matsubayashi et al. (2010) have shown that the reproductive isolation process may comprise multiple components. For instance, six incomplete isolation mechanisms are known to occur in two closely related species of the phytophagous ladybird beetles, Henosepilachna vigintioctomaculata and $H$. pustulosa, resulting jointly in almost complete reproductive isolation. Studies on multiple components of reproductive isolation are rare but are required if we are to understand which barriers contribute to speciation and how different barriers might interact (Coyne and Orr, 2004). In line with this complex establishment of reproductive isolation between host-affiliated species of phytophagous insects, we describe here the genetic architecture of the reproductive isolation between two sibling host-affiliated moth species: the European corn borer (ECB, Ostrinia nubilalis Hübner) and the Adzuki bean borer (ABB, Ostrinia scapulalis Walker).

IINRA, UMR CBGP (INRA-IRD-CIRAD-Montpellier SupAgro), Campus International de Baillarguet, Montferrier sur Lez Cedex, France and ${ }^{2}$ CIRAD, UMR AGAP, Montpellier, France

Correspondence: Dr R Streiff, INRA, UMR CBGP (INRA-IRD-CIRAD-Montpellier SupAgro), Campus International de Baillarguet, CS 30016 , F-34988 Montferrier sur Lez Cedex, France.

E-mail: streiff@supagro.inra.fr

This paper is dedicated to the memory of Serge Meusnier.

Received 19 October 2012; revised 16 July 2013; accepted 6 September 2013; published online 13 November 2013 
Genetic, ecological and biological studies in western Europe (Bourguet et al., 2000; Martel et al., 2003; Thomas et al., 2003; Malausa et al., 2007a; Malausa et al., 2007b) have shown that the ECB and ABB are sibling species (Frolov et al., 2007). Each is adapted to its own principal host plants (maize for the ECB and hop, mugwort and hemp for the $\mathrm{ABB}$ ), as shown by host choice for oviposition and larval feeding performance in reciprocal infestation experiments (Bethenod et al., 2005; Calcagno et al., 2007; Malausa et al., 2008). In addition, at least in Western Europe, these two species display strong, but incomplete, reproductive isolation: the ECB and $\mathrm{ABB}$ are interfertile, but the proportion of $\mathrm{F} 1$ hybrids in seminatural (Bethenod et al., 2005) and natural (Malausa et al., 2005) conditions is very low. Much of our research focuses on whether the specialization of ECB on maize- a crop introduced into the native area of Ostrinia spp., that is, Europe, 500 years ago (Tenaillon and Charcosset, 2011)—triggered its ongoing speciation from the $\mathrm{ABB}$, as presumed in 'ecological speciation' theory (Rundle and Nosil, 2005).

The pheromone communication system is a key trait involved in reproductive isolation within the genus Ostrinia (Cardé et al., 1975; Huang et al., 1997; Huang et al., 2002; Thomas et al., 2003; Bontemps et al., 2004; Takanashi et al., 2005). Natural populations of both the $\mathrm{ECB}$ and $\mathrm{ABB}$ have a polymorphic communication system with two different blends of the female sex pheromone. Some females produce a 3:97 mixture of (E)- and ( $Z$ )-11-tetradecenyl acetate (' $Z$ ' females), whereas others produce a 99:1 E/Z blend (' $E$ ' females, Klun, 1975). ' $Z$ ' and ' $\mathrm{E}$ ' males preferentially respond and fly toward a 3:97 E/Z and a 99:1 E/Z blend of female sex pheromones, respectively (Roelofs et al., 1987). Formal genetic studies (Roelofs et al., 1987) and genetic mapping (Dopman et al., 2004; Dopman et al., 2005) have indicated that female pheromone production and the male behavioral response to this pheromone are autosomal and sex-linked traits, respectively, each being determined by a single major gene (designated Pher and resp, respectively, on the map). Finally, a locus encoding a fatty-acyl reductase (pgFar, Lassance et al., 2010; Lassance et al., 2013) has recently been identified as the principal functional gene underlying the Pher quantitative trait loci (QTL) and, thus, the shift from an E to a Z pheromone blend.

This variability of the sex pheromone blend and of the male response ensures a certain level of reproductive isolation between $\mathrm{E}$ and $\mathrm{Z}$ individuals within natural populations of both the ECB and $\mathrm{ABB}$. Indeed, in locations at which $\mathrm{E}$ and $\mathrm{Z}$ individuals coexist (for example, in the United States for the ECB (Linn et al., 1997) and in Japan for the ABB (Takanashi et al., 2005)), the proportions of females producing hybrid blends are lower than what would be expected assuming random mating between $\mathrm{E}$ and $\mathrm{Z}$ moths (Linn et al., 1997). This sex pheromone variation may also be involved in the reproductive isolation between the $\mathrm{ECB}$ and $\mathrm{ABB}$. Indeed, in Europe, sympatric ECB and $\mathrm{ABB}$ females produce $\mathrm{Z}$ and $\mathrm{E}$ blends of pheromones, respectively (Pélozuelo et al., 2004). One straightforward explanation for this would be that the reproductive isolation between these two sibling species is a mere consequence of long-range assortative mating due to differences in female sex pheromones, resulting in the specific attraction of males to females of the same type (Thomas et al., 2003; Pélozuelo et al., 2004). However, experiments in controlled conditions (Pélozuelo et al., 2007) have shown that even when moths are paired in a small box, forcing short-range encounters and, thus, mating between sexual partners, the mating success of $\mathrm{E} \times \mathrm{Z}$ and $\mathrm{Z} \times \mathrm{E}$ crosses remains lower than that of $\mathrm{E} \times \mathrm{E}$ and $\mathrm{Z} \times \mathrm{Z}$ crosses. By crosses and backcrosses of $\mathrm{E}$ and $\mathrm{Z}$ strains, Pélozuelo et al. (2007) have also shown that the close-range mechanism ensuring assortative mating between ECB and ABB moths is unrelated to the type of female pheromone produced. The nature of the trait underlying assortative mating remains elusive, but investigations of this trait may provide new insight into the reproductive isolation between these two sibling species.

In this study, we pursued the characterization of the mating isolation ( $m$ i) between ECB and $\mathrm{ABB}$, by locating QTL linked to this close-range isolation mechanism on a $[\mathrm{ABB} \times \mathrm{ECB}]$ genetic linkage map. On the same map, we also located QTLs linked to Pher and identified the heterochromosome, because of its recurrent role in various traits, some of which being related to sexual selection (including resp (Linn et al., 1997) but also other candidates such as olfactory genes (Lassance et al., 2011)). The location and number of QTLs linked to $m i$ and Pher are discussed in light of previous candidate genes thought to be involved in reproductive isolation. Other characteristics of the interspecific map (segregation distortions and heterozygosity level of the F1 hybrids) are also discussed in light of the process of divergence between these two host-affiliated species.

\section{MATERIALS AND METHODS}

\section{Moth stocks and rearing}

Two strains, one for each sibling species, were used as a source of initial mapping families. The ECB strain was founded from $\sim 100$ pupae taken from an outbred strain reared at INRA-Le Magneraud (France). This strain originated from wild larvae collected from maize (Zea mays L.) in the vicinity of Surgères (France, $46^{\circ} 10^{\prime} \mathrm{N},-0^{\circ} 75^{\prime} \mathrm{E}$ ). The $\mathrm{ABB}$ strain was established and reared at the CBGP-INRA laboratory (France) from $\sim 50$ diapausing larvae collected from mugwort (Artemisia vulgaris L.) near Paris (France, $48^{\circ} 51^{\prime} \mathrm{N}$, $2^{\circ} 21^{\prime} \mathrm{E}$ ) and Lille (France, $50^{\circ} 38^{\prime} \mathrm{N}, 3^{\circ} 03^{\prime} \mathrm{E}$ ) during the spring of 2004 . All strains were reared at $22{ }^{\circ} \mathrm{C} \pm 2{ }^{\circ} \mathrm{C}$ under a $16: 8 \mathrm{~h}$ light/dark photoperiod. Larvae were fed on a standard artificial diet (Gahukar, 1975).

\section{Crossing scheme}

ECB females were crossed with ABB males to obtain F1 hybrids. These hybrids were then individually backcrossed with males or females of the two parental strains. Two backcrosses, C04 and P10, were selected from the several dozen produced, on the basis of their having the largest family sizes obtained at the adult stage (70 offsprings for $\mathrm{C} 04$ and 71 for P10). The C04 and P10 backcrosses correspond to the following pedigrees: [ABB female $\times$ F1 male] for $\mathrm{C} 04$ and [F1 female $\times$ ABB male] for P10 (Figure 1).

\section{Mating assessment}

The level of mating isolation ( $\mathrm{mi}$ ) was measured in a no-choice experiment. Virgin females and virgin males from C04 and P10 backcrosses (Figure 1), within $24 \mathrm{~h}$ of emergence, were paired with an ECB virgin male or virgin female, as appropriate, for three consecutive nights at $22^{\circ} \mathrm{C} \pm 2{ }^{\circ} \mathrm{C}$, with a $16: 8 \mathrm{~h} \mathrm{light/dark}$ photoperiod.

At the end of the third night, females were killed and dissected to determine their mating status (virgin or mated), according to the content of the bursa copulatrix of the genital duct. The sperm and nutritious substances transferred by males during copulation form an easy identifiable solidified structure (the spermatophore) that is later used by females for fertilization.

This mating design excluded sources of isolation other than the short-range acceptance or rejection of mating (for example, mating competition between males, long-distance pheromone attraction, and so on). It thus mainly target the 'Am' (assortative mating) trait described by Pélozuelo et al. (2007). This study demonstrated that a mating barrier exists between the $\mathrm{ABB}$ and $\mathrm{ECB}$ based on quantitative genetics and comparative analysis between intra- and inter-specific mating trials. Yet, by contrast with the comparative analysis based on multiple crosses in the study by Pélozuelo et al. (2007), the present phenotype measurements do not distinguish between the reproductive isolation between the $\mathrm{ABB}$ and $\mathrm{ECB}$, and other intrinsic individual propensities 


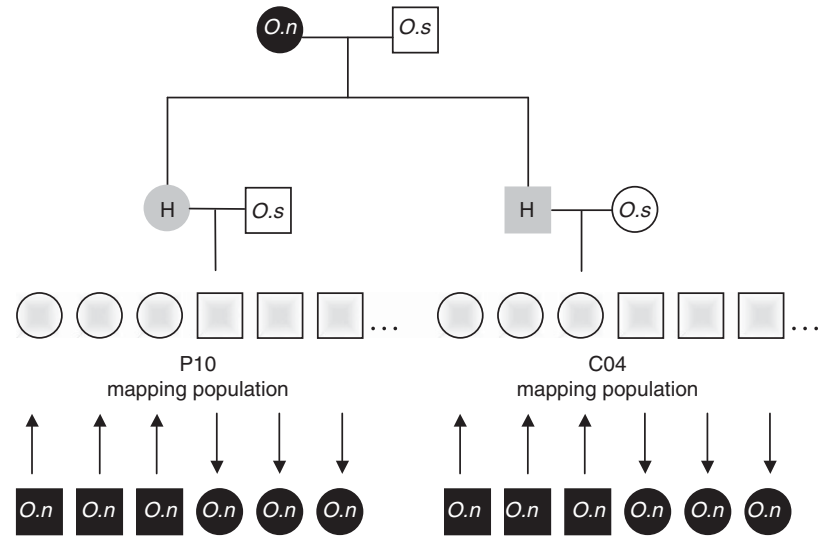

Figure 1 Experimental design for $\mathrm{ECB}$ and $\mathrm{ABB}$ crosses and backcrosses. Circles and squares represent females and males, respectively. Individuals from parental strains are shown in black (for the ECB strain) and white (for the ABB strain). F1 hybrids are shown in gray and the offsprings of backcrosses are shown by pale gray graduated shading. Lines indicate crosses (mapping scheme), and arrows indicate the mating experiment ( $m$ QTL experiment). 'O. $n$ ' is for Ostrinia nubilalis (ECB), 'O.s' for O. scapulalis $(A B B)$ and $\mathrm{H}$ for hybrid.

to mate. We thus distinguish the mating isolation (mi) trait measured here from the Am trait observed in the study of Pélozuelo et al. (2007).

\section{Female sex pheromone characterization}

Before dissecting female offspring of the $\mathrm{C} 04$ and P10 backcrosses to determine their mating status, we extruded the pheromone glands by pressing gently on the abdomen. Individual glands were incubated for $20 \mathrm{~min}$ in $20 \mu \mathrm{l}$ of $99 \%$ hexane (Prolabo, Fontenay-sous-Bois, France) for pheromone extraction. The extract was then stored at $-20^{\circ} \mathrm{C}$. We analyzed $3 \mu \mathrm{l}$ of the frozen mixture on a gas chromatograph, as described by Pélozuelo et al. (2007). Pure synthetic $\mathrm{E}$ and $\mathrm{Z}$ isomers of the female sex pheromone were used as internal standards. Pheromone characterization was performed on the female offspring of the P10 backcross only, for external reasons.

\section{AFLP genotyping protocol}

DNA was extracted with the DNeasy Kit (Qiagen, Venlo, Netherlands), according to the manufacturer's protocol, from the heads of adults stored in ethanol. DNA concentration was assessed by fluorimetric quantification of dsDNA with the PicoGreen Kit (Life Technologies, Carlsbad, CA, USA). AFLP analyses were conducted as described by Midamegbe et al. (2011). Briefly, we digested $\sim 100 \mathrm{ng}$ of genomic DNA with EcoRI and BamHI (Promega, Madison, WI, USA) enzymes, and then carried out two successive selective PCRs with the EcoRI (5'-GACTGCGTACCAATTC-3') and BamHI + A (5'ATGAGTCCTGATGATCCA- $3^{\prime}$ ) primers for the first reaction and the $E c o R I+2$ and $B a m H I+3$ primers for the second reaction. In total, 16 pairs of $E c o \mathrm{RI}+2$ and $B a m \mathrm{HI}+3$ primers were used. AFLP products were subjected to electrophoresis on an ABI 3130XL (Applied Biosystems, Foster City, CA, USA) automated sequencer. Raw data were analyzed with GENEMAPPER (Applied Biosystems, Foster City, CA, USA) version 4.0 software and individuals were scored for the presence or absence of each AFLP marker.

\section{Tpi genotyping}

The gene encoding triose phosphate isomerase ( $T p i)$ has been shown to be sexlinked in the ECB (Glover et al., 1990). It is located close to a QTL contributing to the male response to female sex pheromone blend (resp locus, Dopman et al., 2004). In this study, we mapped Tpi as follows. The DNA sequences obtained by Malausa et al. (2007b) were used to identify an EcoRI restriction site overlapping a SNP distinguishing between the ABB and ECB. Using primers flanking this restriction site (forward: 5 '-GCCCAAGACGTCCA CGCTGC- $3^{\prime}$ and reverse: $5^{\prime}$-TCTCCGCATGATACTTGAGA-3'), we amplified this fragment of Tpi from the parents and offspring of the C04 backcross, by PCR, as follows: $5 \mathrm{~min}$ at $95^{\circ} \mathrm{C}, 30$ cycles of $30 \mathrm{~s}$ at $95^{\circ} \mathrm{C}, 30 \mathrm{~s}$ at $60^{\circ} \mathrm{C}$ and $1 \mathrm{~min}$ at $72^{\circ} \mathrm{C}$, followed by $10 \mathrm{~min}$ at $72^{\circ} \mathrm{C}$. The PCR products were then digested with EcoRI, according to the manufacturer's protocol. Digestion products were run in a $2 \%$ agarose gel and stained with ethidium bromide. The F1 male of the C04 backcross had two alleles for the target SNP (mixture of cut and uncut PCR fragments). Conversely, the ABB female of this backcross appeared to be homozygous. We then examined the segregation of the male parental alleles in the offspring of the C04 backcross.

\section{Mapping analysis}

No crossing over occurs during oogenesis in Lepidoptera, so that all the markers on the same chromosome are inherited as a single unit (that is, without recombination) from the female parent (Heckel et al., 1999). Conversely, crossing over does occur during spermatogenesis in males, making it possible to carry out crosses in which recombination affects the cosegregation of markers on the same chromosome as a function of the distance between markers.

Based on this unusual feature of female recombination in these species, four linkage maps were constructed as follows. The first two maps were based on the segregation of markers (i) present in the F1 male and absent from the ABB female of the C04 backcross, and (ii) present in the F1 female and absent from the ABB male of the P10 backcross. These two maps show the patterns of segregation of markers present in the F1 hybrid parent. We also constructed two other maps, based on the reverse configuration: markers present in the $\mathrm{ABB}$ female and absent from the F1 male of the C04 backcross, and present in the ABB male and absent from the F1 female of the P10 backcross. These two maps provided the pattern of segregation of markers present in the $A B B$ parent.

We also made use of recombination patterns in the generation of these four maps: for each backcross, markers present in the female and absent from the male cosegregate as a single unit if they are located on the same chromosome. We therefore obtained what we refer to hereafter as a 'chromosomal map'-a map on which all markers from the same linkage group display the same pattern of segregation in a given family (with the exception of mutations and/ or typing errors). For clarity, these maps are referred to as NR_P10 and NR_C04 maps, where NR means 'non recombinant' and C04 or P10 refer to the segregating backcrosses. Conversely, when markers are present in the male parent and absent from the female parent, recombination occurs and classical genetic maps are obtained, showing the ordering of and distances between the markers defining the pattern of recombination in the offspring. These maps are referred to as the R_C04 and R_P10 maps, where 'R' means recombinant and C04 or P10 indicates the segregating backcross concerned.

In summary, NR_P10 is a chromosomal map for an F1 female hybrid, R_C04 is a linkage map for an F1 male hybrid, NR_C04 is a chromosomal map for an ABB female parent and R_P10 is a linkage map for an ABB male parent (Figure 1).

Linkage analysis was performed with Joinmap4.0 software (Stam, 1993). Linkage maps were based on 'informative' AFLP markers, that is, those that were heterozygous in the mapped parent. Chi-squared $\left(\chi^{2}\right)$ tests were performed on informative AFLP markers to check the goodness-of-fit for the expected 1:1 Mendelian segregation ratio of each marker in the offspring. Loci with distorted segregation patterns deviating significantly from this ratio with $P<0.001$ were excluded from map construction to avoid pseudo-linkages (that is, 22, 19, 11 and 15 AFLP markers in R_C04, NR_P10, NR_C04 and R_P10, respectively). Linkage groups were then identified on the basis of a logarithm of odds (LOD) score of 8 in NR_P10 and NR_C04, and 6 in R_P10 and R_C04. The haploid number of chromosomes in Ostrinia spp. is $n=31$ (Guthrie et al., 1965). We therefore expected to obtain 31 linkage groups.

For R_C04 and R_P10, the ordering of the markers within linkage groups was determined by maximum likelihood and default parameters, in Joinmap. Recombination values were converted into map distances (in centimorgans, cM) by applying the Kosambi mapping function (Kosambi, 1944).

The genus Ostrinia, like most lepidopterans (Sahara et al., 2012), has a female-heterogametic sex chromosome system: males and females are ZZ and WZ, respectively. Hence, the Z heterochromosome was recognized in R_C04 as 
the linkage group bearing the Tpi locus. In chromosomal maps (NR_C04 and NR_P10), it was recognized on the basis of the segregation pattern of Z-linked markers: in such maps, the F1 parent was female and the mapped markers were present in the female parent and absent from the male parent and segregated in the offspring. The segregation pattern is thus that of a $(\mathrm{ZAW})$ female $\times(\mathrm{ZaZa})$ male cross, where $a$ indicates an absence of the AFLP band, and $A$ indicates its presence. The male and female offspring would be expected to be $\mathrm{ZAZa}$ and $\mathrm{ZaW}$, respectively. We thus introduced a virtual marker into the data set with the sex of each offspring, and simple ordering of the AFLP markers made it possible to identify those that were Z-linked.

\section{Clustering of markers}

The number of AFLP markers per linkage group in the four maps was compared with the number expected under a Poisson distribution, to test the randomness of the distribution of AFLP within the genome, with the 'goodfit' function and ks.test of the 'vcd' library in R/qtl software (available from http: //www.rqtl.org/). The same tests were applied to the distribution of the distances between two consecutive markers within linkage groups for R_C04 and R_P10. The results of this second analysis are directly dependent on the bin sizes used to calculate frequencies (Winter and Porter, 2009). We used a bin size of $2 \mathrm{cM}$.

\section{QTL analysis}

QTL analysis was carried out with binary values obtained in the $m i$ experiment, coded as 0 for non-mated individuals and 1 for mated individuals. Pheromone type was also analyzed in the P10 offspring as a binary trait corresponding to two classes of pheromone: $\mathrm{E}$ and $\mathrm{E} / \mathrm{Z}$ (hybrids). Computational analysis was carried out with R/qtl software (available at http: // www.rqtl.org/) as previously described (Broman et al., 2003). QTL detection was performed by interval mapping (Dempster et al., 1977) in R_C04 and R_P10 and by marker regression in NR_C04 and NR_P10 (because of the lack of recombination in these maps), with the binary model recommended for binary phenotypic traits (Broman et al., 2003). LOD significance thresholds for QTLs were established with 1000 permutations, as described by Churchill and Doerge (1994), with a procedure adapted to the heterochromosomes, as recommended by Broman et al. (2006) and implemented in R/qtl (Broman et al., 2003).

\section{RESULTS}

\section{Linkage maps}

In total, 323 and 165 AFLP markers were informative (that is, heterozygous in the F1 parents) in R_C04 and R_P10, respectively (Figures 2 and 3). The number of informative markers is directly related to the level of heterozygosity in the F1 and the degree of divergence between the parental lines.

We obtained 31 and 27 linkage groups for R_C04 and R_P10, respectively, with a LOD score of 6 . The total length of the map was 997 cM for R_C04 and 595 cM for R_P10, with the length of linkage groups ranging from 1.8 to $36.2 \mathrm{cM}$ in R_C04 and 1.5 to $60.1 \mathrm{cM}$ in R_P10. The difference in map length between the two families likely reflects a lack of saturation of R_P10 (less linkage groups and less markers). The mean distance between two consecutive markers was of $3.8 \mathrm{cM}$ in R_C04 and $6.1 \mathrm{cM}$ in R_P10. Forty-three (17) markers remained unlinked in R_C04 (R_P10).

\section{Chromosomal maps}

In total, 234 and 215 AFLPs were informative in NR_P10 and NR_C04, respectively. Linkage analysis identified 31 groups of cosegregating markers in NR_P10 and 29 in NR_C04 (Figures 4 and 5). The pattern of marker cosegregation was consistent with the lack of recombination in female lepidopterans, with the exception of $0.73 \%$ genotyping error and/or mutations for NR_P10 and $1.00 \%$ for NR_C04, as estimated by counting the unexpected genotypes in the pattern of cosegregation obtained. The number of markers per linkage group varied from 2 to 15 in NR_P10 and from 2 to 14 in NR_C04. Twenty-six markers remained unlinked in NR_P10 and three in NR_C04.

\section{Linkage groups and distribution of AFLP markers}

We found 31 linkage groups in the R_C04 and NR_P10 maps, corresponding to the haploid number of chromosomes in the genus Ostrinia (Guthrie et al., 1965). The number of linkage groups identified was lower for both NR_C04 (29) and R_P10 (27). This probably reflects the lower level of saturation of these maps.

The distributions of AFLP markers between linkage groups did not differ significantly from random expectations in R_C04 $\left(\chi^{2}=5.02\right.$, d.f. $=4, P=0.285)$ and NR_C04 $\left(\chi^{2}=6.78\right.$, d.f. $\left.=4, P=0.148\right)$, whereas weak deviations from random expectations were observed for R_P10 $\left(\chi^{2}=10.73\right.$, d.f. $\left.=4, P=0.030\right)$ and NR_P10 $\left(\chi^{2}=14.90\right.$, d.f. $=5, P=0.011)$. However, all the $\chi^{2}$ values were in the same order of magnitude.

Within linkage groups, the frequency distribution of the distances between consecutive markers in R_C04 and R_P10 showed the markers to be significantly clustered (R_C04, $\chi^{2}=345.93$, d.f. $=6$, $P<10^{-4}$, and R_P10, $\chi^{2}=111.50$, d.f. $\left.=\overline{6}, P<10^{-4}\right)$.

\section{Bridge markers between maps}

Eighty of the 937 AFLP markers were mapped on at least two of the four maps. No marker was mapped on both R_C04 and NR_C04 because, in these maps, the informative markers were in opposite configurations (that is, present in the F1 male and absent from the female parent in R_C04, but absent from the F1 male parent and present in the female parent in NR_C04, see Materials and Methods). The same reasoning holds for R_P10 and NR_P10.

Details of the bridge markers between maps are provided in Supplementary Figure S1. In brief, three, two, five and one linkage group were connected by two or more markers between R_C04 and NR_P10, R_P10 and NR_C04, NR_P10 and NR_C04, and NR_P10 and R_C04, respectively. Total concordance was observed for these markers. Thus, any two markers found to belong to the same linkage group in one map also belonged to the same linkage group on another map (provided they were present on that map).

\section{Segregation distortion}

The markers showing a strong deviation to $1: 1$ segregation $\left(\chi^{2}\right.$-test, $P<0.001$ ) were discarded prior to maps' construction (see Materials and Methods). Weaker segregation distortion was observed for 36, 14, 29 and 7 loci $(0.001<P<0.050)$ in R_C04, NR_P10, NR_C04 and R_P10, respectively. After linkage analyses, 22, 13, 26 and 4 of them were mapped to linkage groups in R_C04, NR_P10, NR_C04 and R_P10, respectively. In total, with a significance threshold of 0.05 , distorted loci accounted for 18,14, 19 and 13\% of the screened markers in R_C04, NR_P10, NR_C04 and R_P10, respectively.

In all four maps, loci with distorted segregation patterns were highly clustered both within and between linkage groups. In R_C04, the markers with distorted segregation were present in only 6 of the 31 linkage groups. Some linkage groups displayed segregation distortion in highly localized areas (e.g., linkage groups 3, 13 and 27; Figure 2). Conversely, linkage group 19 displayed distortion over almost its entire length and linkage group 14 displayed distortion over half its length. In R_P10, all the distorted (and mapped) markers were present in only 1 of the 28 linkage groups identified (linkage group 5, Figure 3).

In NR_P10 and NR_C04, in which there was no recombination within linkage groups, a similar pattern was observed, with three 


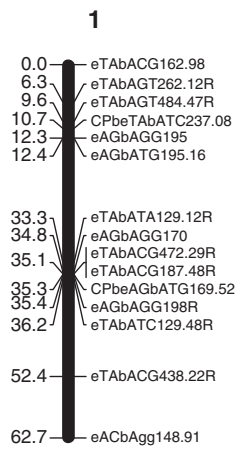

7

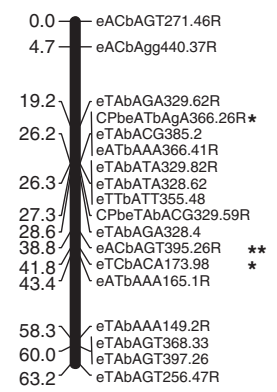

13

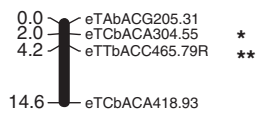

19

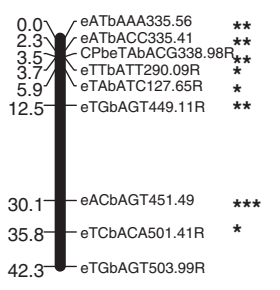

25

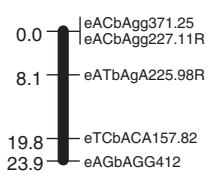

26

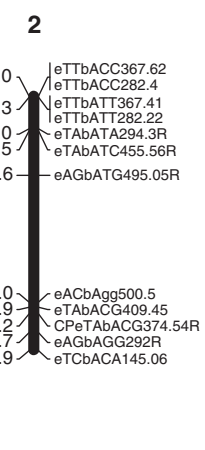

8

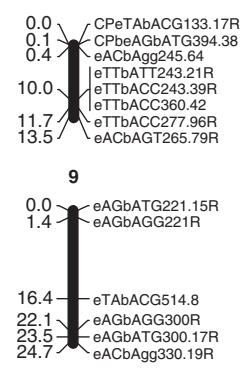

14

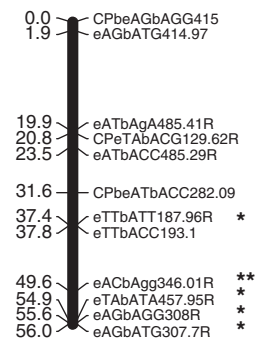

20

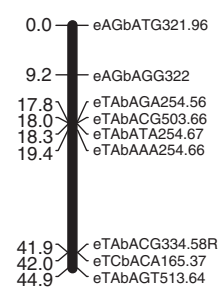

27

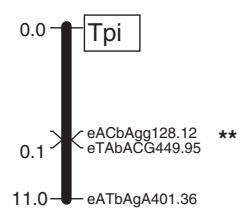

3
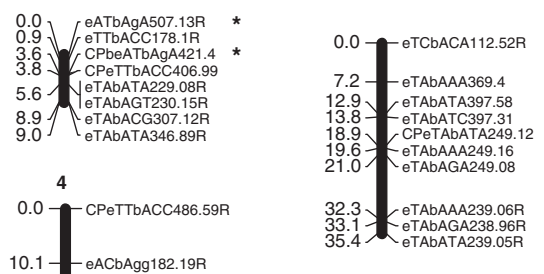

11

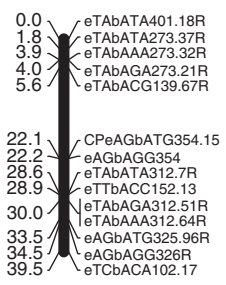

16

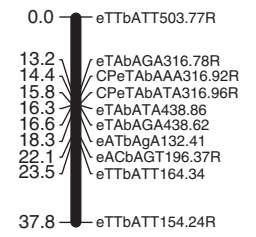

23

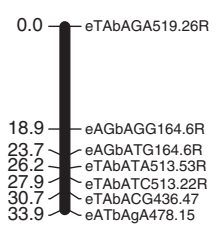

29

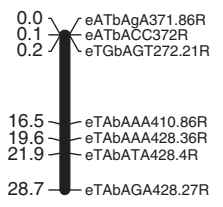

28

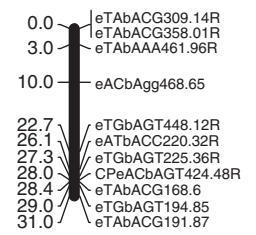

6

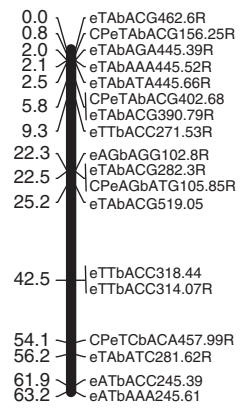

12

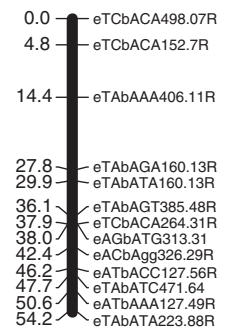

17

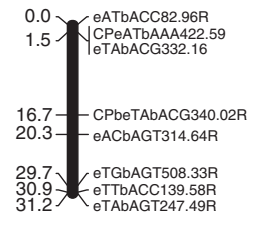

18

10.2-CPeACbAgg399.12

24

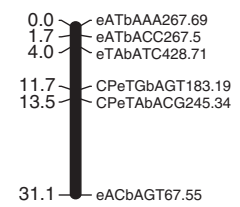

30

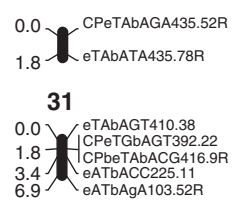

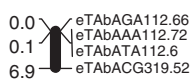

Figure 2 R_C04 linkage map. Vertical black bars correspond to linkage groups. Linkage group IDs are given above each bar. Horizontal fine bars correspond to AFLP marker positions, with the distance (in centimorgans, cM) on the left and the marker ID on the right. The Tpi marker (see Materials and Methods), identifying linkage group 27 as the $Z$ heterochromosome, is bounded by an open black square. Black stars highlight markers displaying distorted segregation, ${ }^{*} P<0.050,{ }^{*} P \leqslant 0.010$ and $* * * P \leqslant 0.001$. 


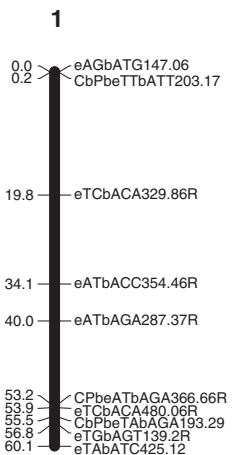

6

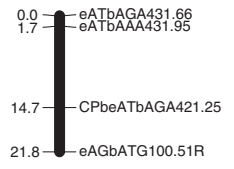

12

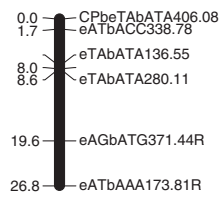

17

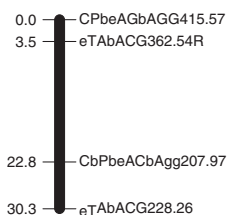

$30.3-$ eTAbACG228.26 $_{\text {en }}$

22

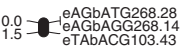

23

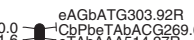

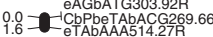

2

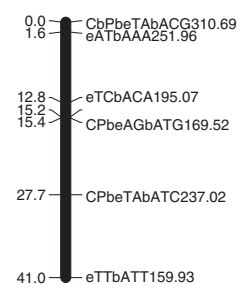

7

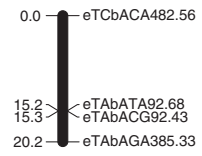

13

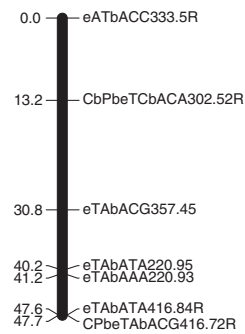

18

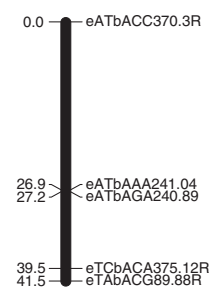

25

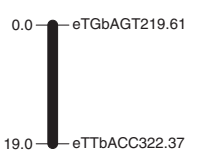

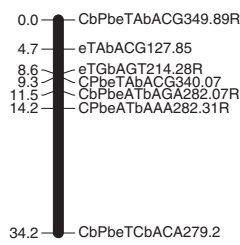

8

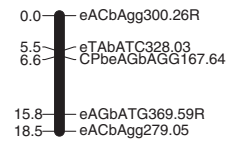

9

0.0
1.7
eACbAgg $406.14 \mathrm{R}$

14
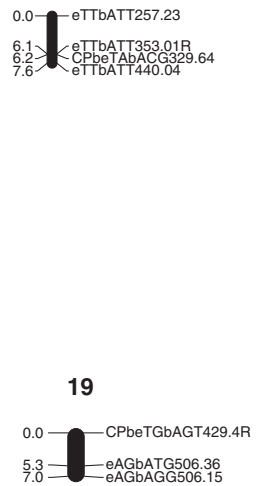

26

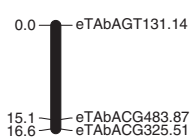

\section{4}

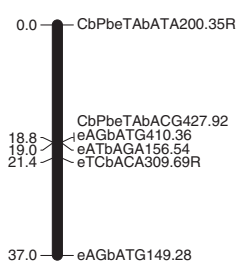

10

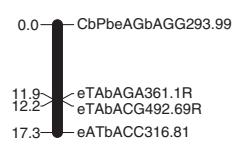

15

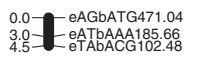

5

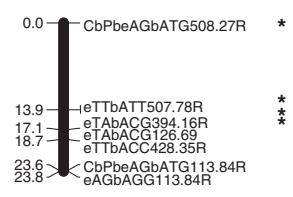

11

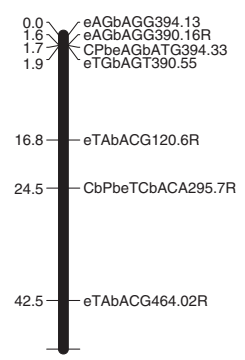

16

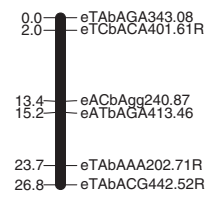

20
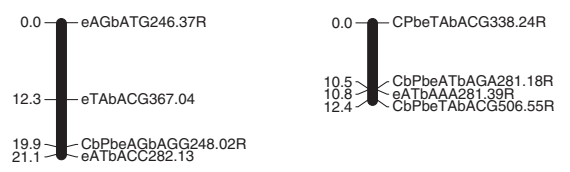

Figure 3 R_P10 linkage map. Vertical black bars correspond to linkage groups. Linkage group IDs are given above each bar. Horizontal fine bars correspond to AFLP marker positions, with the distance (in centimorgans, cM) on the left and the marker ID on the right. Black stars highlight markers displaying distorted segregation, ${ }^{*} P<0.050,{ }^{*} P \leqslant 0.010$ and $* * * P \leqslant 0.001$. The initial coding of linkage group names was retained throughout the entire mapping process, leading, by chance, to the omission of linkage group 24 . We retained the initial IDs to prevent errors in subsequent analyses.

groups displaying high levels of segregation distortion in both NR_P10 and NR_C04 (Figures 4 and 5). In NR_P10 and NR_C04, this pattern should be 'perfect', with any distortion within a given linkage group affecting all the markers from that group, as they are fully linked. However, as noted before, some genotyping errors (or mutations) and missing data may account for these discrepancies. 


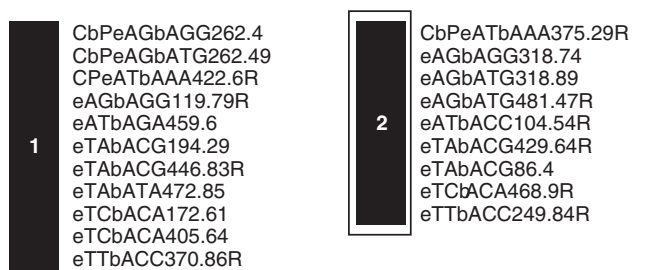

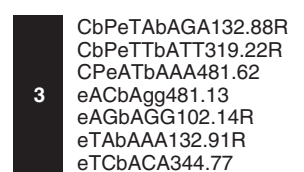

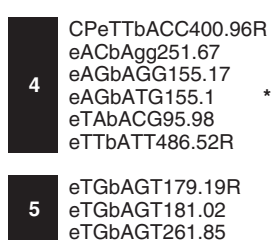

eTGAGT181.02

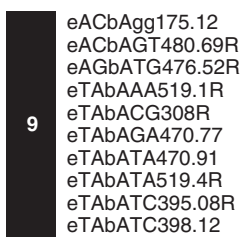

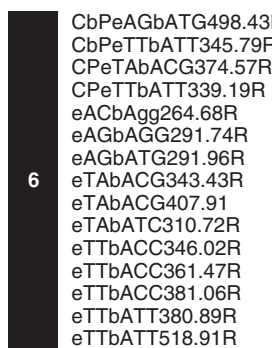

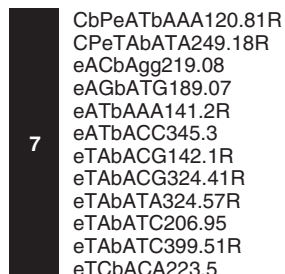

TTCATT18.91R
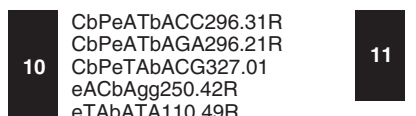

eACbAGT160.8 eATbACC367.52R * eATbAGA266.52R * eACbAgg250.42R eTAbATA110.49R
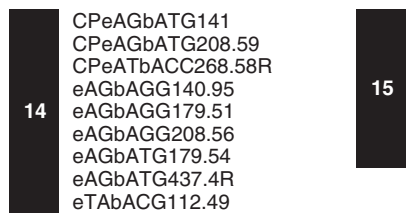

CPeAGbATG105.95 CPeTAbACG135.25 CPeTAbACG402.72R CPeTCbACA457.98 eAGbAGG105.77 eTAbACG221.6 eTABATC 136.45

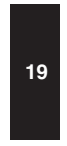

CPeTAbAAA316.79R CPeTABATA316.93R CPeTAbATA316.93R
eTAbACG336.72 eTADACG336.72
eTAbAGA218.09 eTAbAGA218.09 eTCbACA250.2 eTTbATT150.83R

eTAbATA402.75R eTAbATA402.75R
eTAbATC243.18R

CbPeAGbAGG250.78 CPPeAGBAGG250.78 CPeAGbATG354.

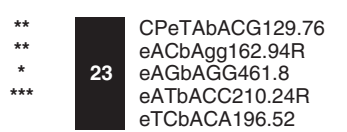

eTCbACA196.52
CPeTAbACG245.38 eTAbACG 457.94
eTCbACA333.46

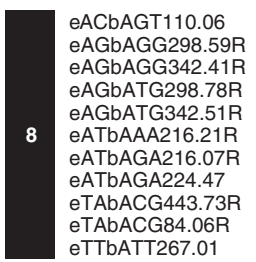
eAGbAGG298.59R eAGbAGG342.41R eAGbATG342.51R eATbAAA216.21R eATBAA216.07R eTAbACG443.73R eTAbACG84.06R
12 CPeATbAGA503.48R eAGbAGG124.33R eAGbAGG197.05 eAGbAGG457.19 eTCbACA298.32R eTCbACA314.65

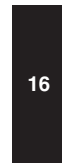
CbPeTAbATC415.02R CPeTAbAAA425.75 CPeTAbATA425.89 eATbACC423.26R eTAbATC329.75 eTAbATC363.96 TCDACA316.51R

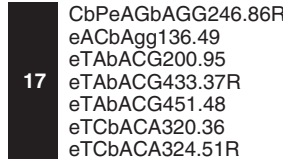
CbPeTAbAAA433.67
24 eTAbATC411.96R ETCbACA102.22R eTTbATT405.07R

Figure 4 NR P10 chromosomal map. Vertical black bars correspond to linkage groups, with group ID shown in white. As no recombination occurs in the female parent, all markers within a linkage group are inherited without recombination, so it was not possible to calculate genetic distances in this pedigree. Black stars indicate markers with distorted segregation, ${ }^{*} P<0.050,{ }^{*} P \leqslant 0.010$ and ${ }^{* * *} P \leqslant 0.001$. The Z heterochromosome was identified here as linkage group 2 (framed in black), on the basis of the particular pattern of segregation expected and observed for Z-linked markers (see Materials and Methods).

\section{QTL detection}

For the pheromone production (Pher) trait, one significant QTL was found in linkage group 1 in NR_P10 (LOD $\left.=4.86, P<10^{-4}\right)$, accounting for $75 \%$ ( $a$, additive effect) of the phenotypic variation (Figure 6). In the same pedigree, but on the R_P10 map, a significant QTL was also identified for Pher in linkage group $9(\mathrm{LOD}=2.57$, $P=0.048, a=58 \%$, Figure 6).
For the mating isolation ( $m i$ ) trait, we found two significant QTLs in the NR_P10 map (linkage group 3, LOD $=2.51, P=0.028, a=37 \%$ of the phenotypic variation; linkage group $4, \mathrm{LOD}=2.65, P=0.023$, $a=38 \%$ of the phenotypic variation, Figure 7) and one QTL in the NR_C04 map (linkage group $8, \mathrm{LOD}=2.32, P=0.035, a=37 \%$ ). As no recombination occurred in the F1 female parent for NR_P10 and NR_C04, no genetic distance could be inferred between markers, and 
CbPbeACbAgg207.98 CbPeTGbAGT319.02 CbPeTTbATT319.25 eACbAGT76.57 EATbACC 372.77 eTAbAAA196.45 eTABACG465.88R eTCbACA415.63
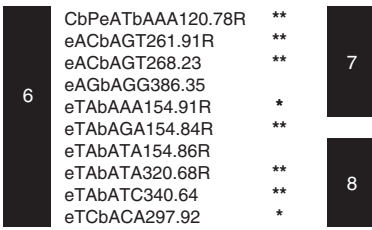

eACbAgg271.4 EATbAAA215.44 eATbAgA215.32 eATbAgA216.3 CbPeATbAgA296.47 CbPeTAbACG327.03 eAGBAGG501.66R eTAbACG257.2
eTAbAGT88.95R eTCbACA297.92 CbPeATbAAA375.22 CbPeTGbAGT474.84 eACbAgg 199.08 eTAbACG114.64 eTTbAAC249. 8

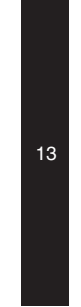

CbPbeAGbATG113.86R CbPbeAGbATG508.25 CbPeTAbATA297.22 eAGbATG95.83R eATbAAA181.99 eATbACC298.56 eATbAgA 181.93 eTAbACG118.99 eTGbAGT299.71R ETTbAAC239.82 ETTbAAC428.27R eTTbATT239.63 eTTbATT261.1 eTTbATT507.67R
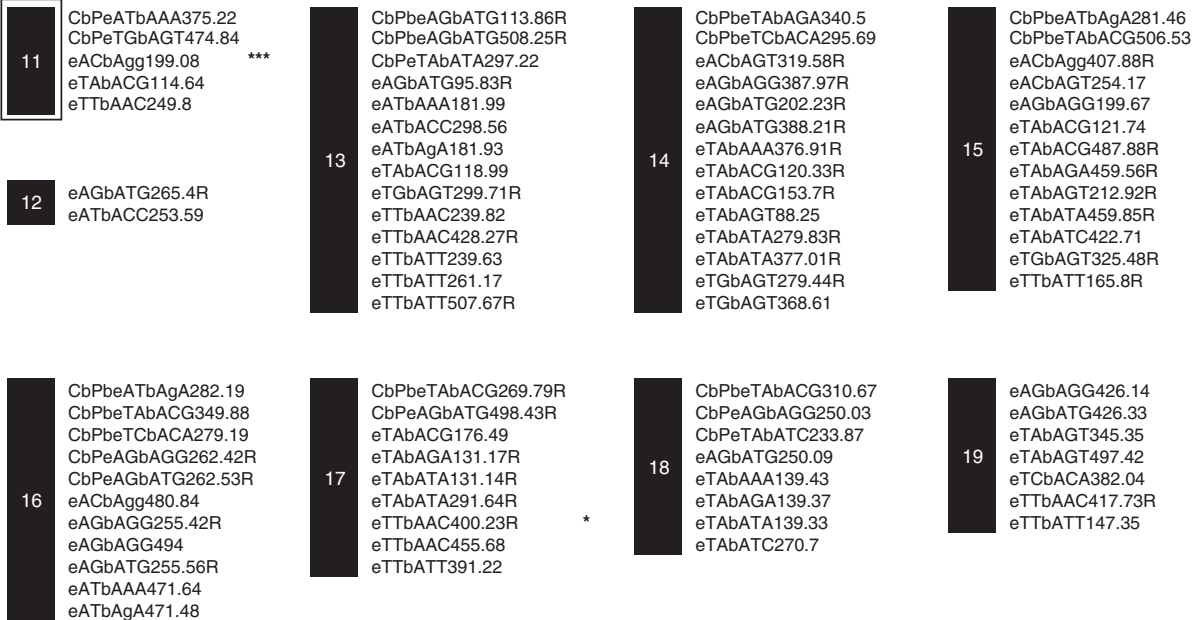

CbPbeTAbACG427.04R eACbAgg 352.78 eTAbACG109.89 eTCbACA459.94R

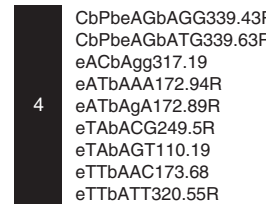

eATbAgA471.48
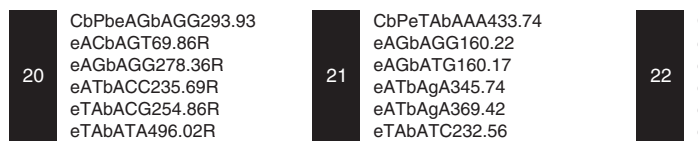

CbPbeACbAgg263.2R eAGbAGG313.83 eATbAAA404.45 eATbACC 159.65 eATbAgA462.52 eTTbATT469.64

CbPbeTAbACG310.67 CbPeAGbAGG250.03 CbPeTAbATC233.87 eAGbATG250.09 eTAbAAA139.43 ETAbAGA139.37 eTADATA139.33
eTAbATC270.7

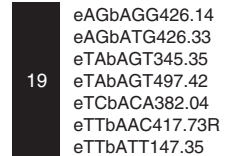

CbPbeTAbAGA193.29R CbPbeTTbATT203.18R CbPeTAbATC415.0 eTAbAGT360.46 eTAbATA193.3R ETAbATA388.02 eTCbACA328.11
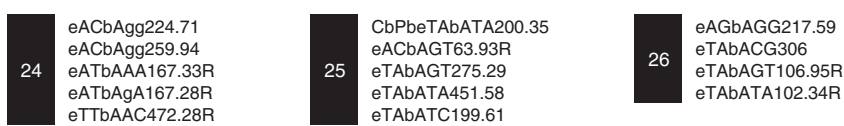

Figure 5 NR_CO4 chromosomal map. Vertical black bars correspond to linkage groups, with group ID shown in white. As no recombination occurs in the female parent, all markers within a linkage group are inherited without recombination, so it was not possible to calculate genetic distances in this pedigree. Black stars indicate markers with distorted segregation, ${ }^{*} P<0.050,{ }^{*} P \leqslant 0.010$ and ${ }^{* * *} P \leqslant 0.001$. The $Z$ heterochromosome was identified here as linkage group 11 (framed in black), on the basis of the particular pattern of segregation expected and observed for Z-linked markers (see Materials and Methods). The initial coding of linkage group names was retained throughout the mapping process, leading, by chance, to the omission of linkage group 9. We retained these IDs to prevent errors in subsequent analyses.

the QTLs identified on these maps are attributable solely to linkage groups, without further information on the location within these groups. All the linkage groups bearing QTLs involved in Pher and $m i$ were autosomal.

\section{DISCUSSION}

The goals of this study were (i) to characterize the genetic architecture of a trait (mating isolation, mi) involved in the reproductive isolation between two sibling species of the genus Ostrinia and (ii) to confirm its independence from another trait (the production, by females, of a sex pheromone, Pher) involved in reproductive isolation and previously mapped in the ECB (Dopman et al., 2004). We produced genetic maps based on $[\mathrm{ABB} \times \mathrm{ECB}] \times \mathrm{ABB}$ backcrosses, for QTL detection and localization. These interspecific pedigrees provided information about the degree of heterozygosity of the F1 hybrid parents (estimated by determining the number of informative markers, see Results) and segregation distortion in the offspring. Both these parameters can be considered in light of the divergence between the parental species (the ECB and $\mathrm{ABB}$ ). 

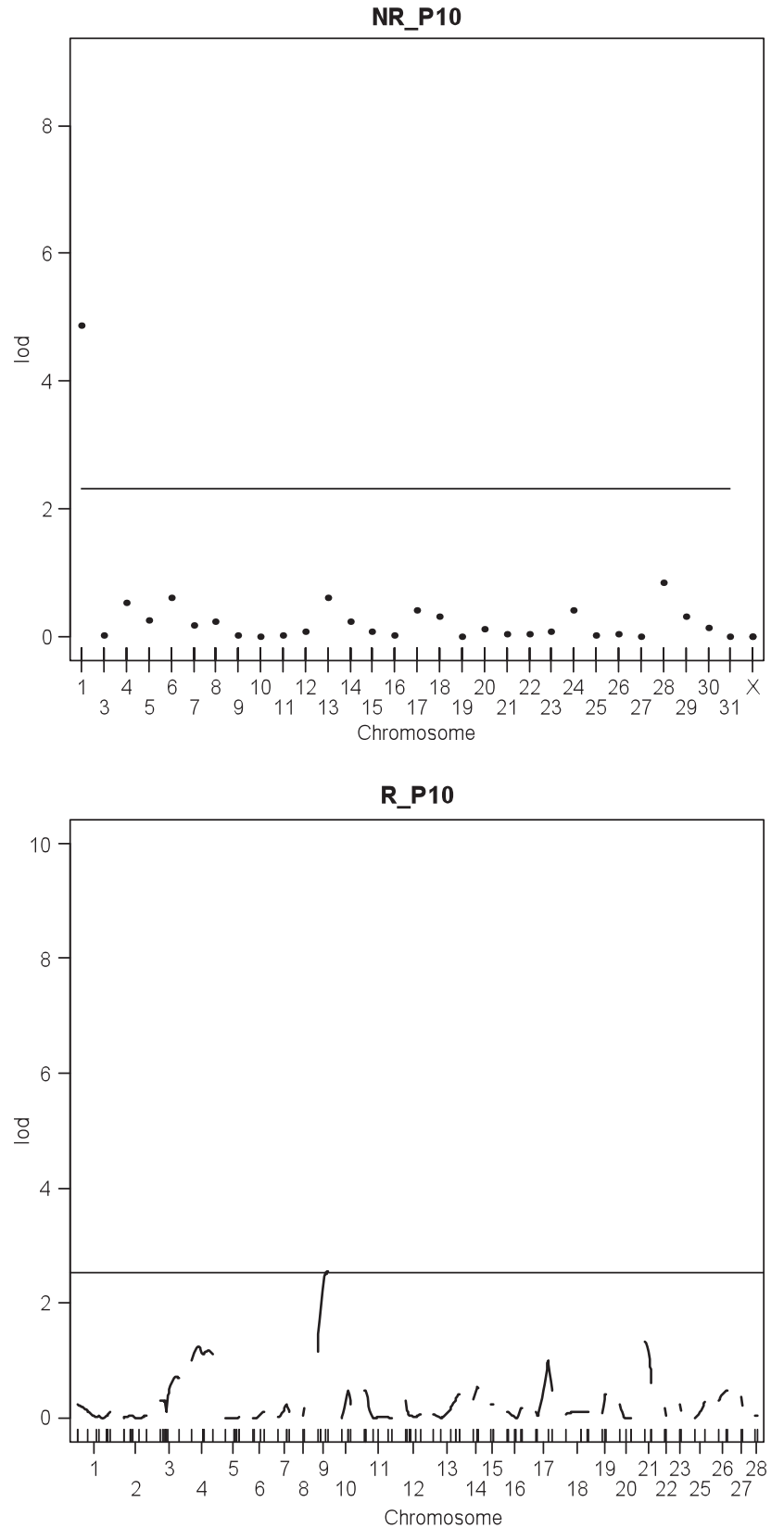

Figure 6 QTL scan for the pheromone production (Pher) trait. QTL for all autosomal and $Z$ heterosomal (labeled ' $\mathrm{X}$ ', shifted in the last position) linkage groups in R_P10, NR_P10. In NR_P10, the LOD score is plotted against each linkage group, represented by a single point, due to the absence of recombination in the female parent (genotyping/mutation errors were manually corrected in the corresponding files).

\section{Species differentiation and genome}

Two of the four maps (NR_P10 and R_C04) provided information about segregation in the F1 hybrid parents, whereas the other two (R_P10 and NR_C04) provided information about segregation in the ABB parents. We expected hybrid F1 parents to have a larger number of heterozygous markers (referred to as 'informative', see Results) than species-specific parents. Indeed, the F1s should display the diagnostic differences between the two Ostrinia species in addition to the standing variation occurring within species (Winter and Porter, 2009). Our results were consistent with this hypothesis, as for the same genotyping effort, more polymorphic markers (that is, \pm in the mapped parents) were observed in R_C04 (323) and NR_P10 (234) than in NR_C04 (215) and R_P10 (165).

According to Winter and Porter (2009), the ratio of heterozygous markers in F1 hybrid parents versus species-specific parents provides an estimate of the proportion of genome that differs between the species. This proportion was estimated at 33\% in C04 (1-215/323, where 215 and 323 are the number of polymorphic markers in NR_C04 and R_C04, respectively) and 29\% in P10 (1-165/234, with 165 markers in R_P10 and 234 in NR_P10). This level of differentiation is higher than that between Papilio glaucus and P. canadensis (16\%, according to Winter and Porter 2009). However, too few data for mapping comparisons between interspecific and intraspecific pedigrees are available to draw any firm conclusions concerning the level of divergence, as estimated here, between the ECB and ABB.

\section{Segregation distortion and species divergence}

The crossing experiments between the ECB and $\mathrm{ABB}$ performed here and in former studies (Pélozuelo et al., 2007) revealed no hybrid sterility or lack of viability, although this was not formally tested. In the laboratory (Pélozuelo et al., 2007), seminatural (Bethenod et al., 2005) and natural (Malausa et al., 2005) conditions, reproductive isolation seems to be principally prezygotic.

In the four genetic maps produced here, $13-18 \%$ of the polymorphic markers displayed significant segregation distortion. The degree of distortion was similar in 'hybrid' F1 maps (18 and 14\% in R_C04 and NR_P10) and in maps of the ABB parents (10 and $13 \%$ in NR_C04 and R_P10).

Segregation distortion is commonly detected in insect mapping (Solignac et al., 2004; Orr and Irving, 2005; Phadnis and Orr, 2009; Tatsuta and Takano-Shimizu, 2009; Winter and Porter, 2009). It may result, in part, from a sampling effect when offspring sizes are small, or from homoplasy in AFLP markers, leading to segregation at multiple loci being considered as segregation at a single locus (Gort et al., 2006). However, the clustering of distorted markers in localized regions of genomes, as reported here (Figures 2 and 4), probably reveals incompatibilities between divergent parental species, from a distortion of oogenesis to postzygotic selection (Hall and Willis, 2005; Rogers and Bernatchez, 2006). These findings pave the way for studies of the divergent genomic histories of these two Ostrinia species based on new candidate genomic regions other than those including $m i$ and Pher and the $\mathrm{Z}$ heterochromosome (at least in NR_P10, Figure 4). In particular, postzygotic selection may have been neglected in our species complex, but both pre- and postzygotic barriers may be involved in the strengthening of reproductive isolation between the $\mathrm{ABB}$ and ECB (see mutiple components of sexual isolation in phytophagous insects in the study by Matsubayashi et al., 2010).

\section{Genetic architecture of mating isolation}

Our study provides clues to the genetic mechanism underlying the mating isolation $(\mathrm{mi})$ trait, a prezygotic barrier between two sibling species, the ECB and $\mathrm{ABB}$. The fine phenotypic nature of $m i$ is unknown, while the no-choice mating design used in the present study focused on short-range isolation including mechanisms of rejection or acceptance of a sexual partner with a different species background (in line with the Am trait of Pélozuelo et al., 2007) and of individual propensity to mate regardless of the genetic background of the partner. Our results attest that $m i$ is independent of Pher, at least as far as the major genes contributing to these two traits are concerned. Indeed, the QTLs involved in $m i$ and Pher were never 

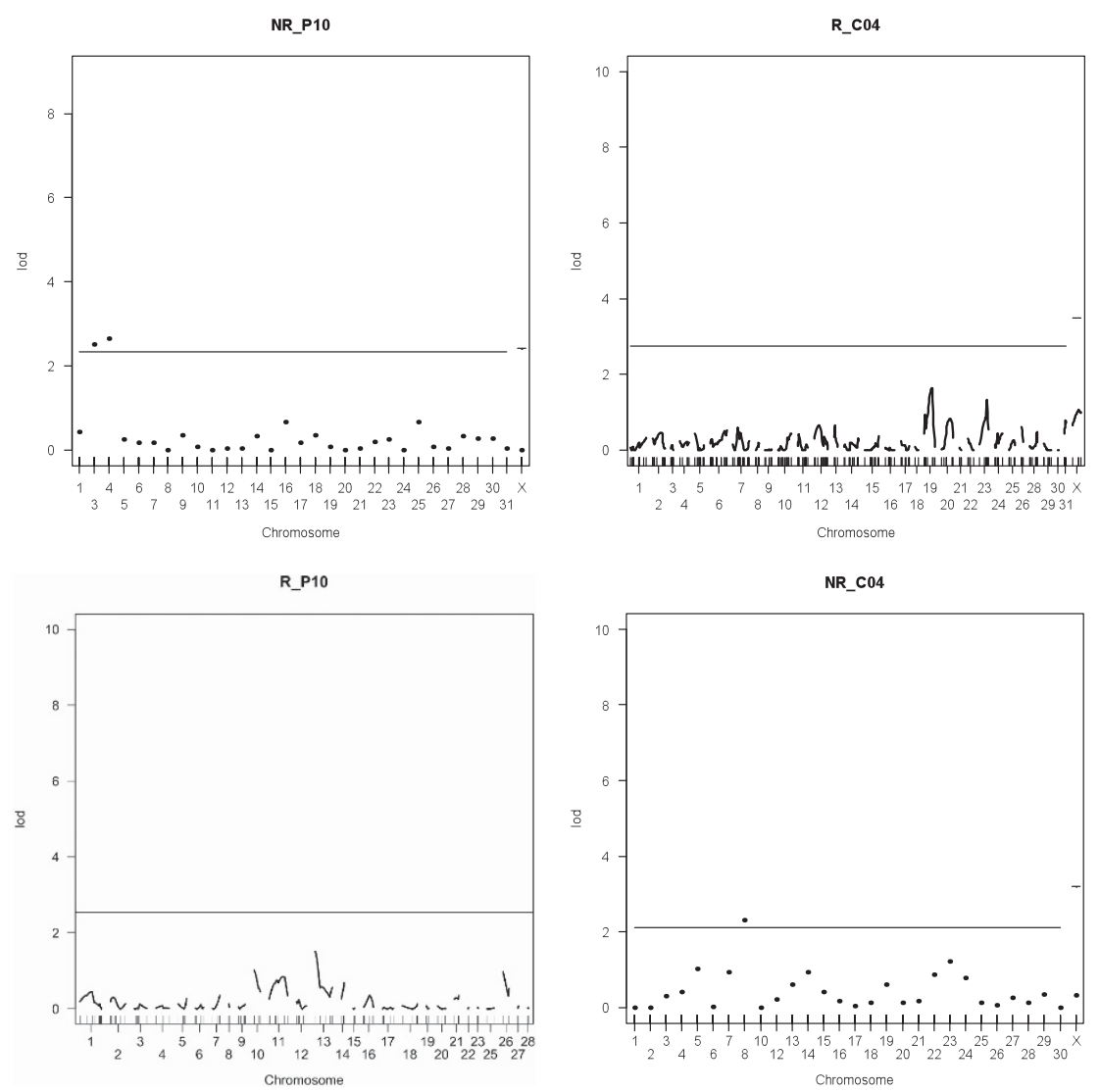

Figure 7 QTL scan for the mating isolation (mi) trait. QTL for all autosomal and Z heterosomal (labeled 'X', shifted in the last position) linkage groups on the NR_P10, R_CO4, R_P10 and NR_CO4 maps. In NR_P10 and NR_CO4, the LOD score is plotted against each linkage group, represented by a single point, due to the absence of recombination in the female parent (genotyping errors and/or mutations were manually corrected in the corresponding files).

assigned to the same linkage groups. In addition, all QTLs involved in mi were autosomal. This location excludes resp, the heterosomal QTL responsible for the behavioral response (and preference) of males to female sex pheromone polymorphism, and the Z-linked pheromone receptor genes recently described in the ECB (Lassance et al., 2011; Yasukochi et al., 2011). These findings are consistent with those of Pélozuelo et al. (2007), who suggested a complete disconnection between an assortative mating trait involved in $\mathrm{ECB} / \mathrm{ABB}$ isolation and the $\mathrm{E} / \mathrm{Z}$ communication system.

It has recently been suggested that, in addition to the reproductive isolation generated by the male response to female sex pheromone, a second prezygotic barrier based on a male pheromone (Royer and McNeil, 1992) to which females respond (Lassance and Löfstedt, 2009) may occur in the genus Ostrinia. The genetic architecture of male pheromone production and of the female response remains unknown and the mi QTLs identified here are potential candidates for further colocalization experiments.

Finally, our findings suggest that the $m i$ trait is controlled by a small number of major genes (two QTLs in NR_P10 and one in NR_C04). However, our experimental design relies on relatively small family sample sizes. This limited sample sizes may induce an overestimation of the additive variance (effect) and an underestimation of the number of QTLs, due to sampling effects (Beavis, 1998). Our results hence may not represent a comprehensive view of the genetic architecture of the trait, but rather a truncated view towards the principal effects while additional undetected factors may be indeed implicated to a lesser extent. Nevertheless, empirical studies carried out on various insect species (but mostly Drosophila) over the last few decades have provided strong evidence that components of reproductive isolation are controlled by a limited number of loci. According to the review by Arbuthnott (2009), the genetic architecture of most of the courtship traits involved in premating isolation involves a few loci of major effect. Moreover, the percentage of phenotypic variance explained is large enough for natural selection to exert an effect through changes at a single locus. This review, based on the many experiments performed on insects from various orders highlighted (i) the importance of premating isolation and its rapid evolution, constituting a key barrier to gene flow in the early stages of speciation (Coyne and Orr, 1998), and (ii) the congruence between empirical data and theoretical expectations concerning the genetic control of courtship. Courtship traits are often controlled by small numbers of loci, which may favor their rapid divergence, in turn driving rapid speciation through premating isolation.

\section{CONCLUSION}

The present study allowed detecting major QTLs involved in mating isolation in the $\mathrm{ABB}$ and $\mathrm{ECB}$. We confirmed that some components of the prezygotic isolation between these two sibling species are independent from the pheromone communication system because mating isolation and pheromone QTLs were located on distinct linkage groups. By design, the present QTL mapping focused on short-range mating isolation in no-choice experiments. Additional 
studies based on different designs (for example, choice mating trials) could target other components of the genetic architecture of reproductive isolation in the genus Ostrinia.

\section{DATA ARCHIVING}

Data available from the Dryad Digital Repository: doi:10.5061/ dryad.qr3t2.

\section{CONFLICT OF INTEREST}

The authors declare no conflict of interest.

\section{ACKNOWLEDGEMENTS}

We thank C Billot, F Ceirqueira and E Desmarais for their assistance in molecular experiments. AFLP data used in this work were partly produced through the technical facilities of the CeMEB ("Centre Méditerranéen de l'Environnement et de la Biodiversité"). This work was supported by two grants, one from the INRA Research Department 'Santé des Plantes et Environnement' (through the 'GAPS' (Genetics of Adaptation of Pest Species) project) and one from INRA-CIRAD (through the 'SDIPS' (Mechanisms of Speciation and Molecular Diagnosis of Insect Pest Species Complexes) project).

Arbuthnott D (2009). The genetic architecture of insect courtship behavior and premating isolation. Heredity 103: 15-22.

Beavis W (1998). QTL analyses: power, precision, and accuracy. In: Paterson AH (eds) Molecular Dissection of Complex Traits. CRC Press: Boca Raton, FL, USA pp 145-162.

Berlocher SH, Feder JL (2002). Sympatric speciation in phytophagous insects: moving beyond controversy? Ann Rev Entomol 47: 773-815.

Bethenod MT, Thomas Y, Rousset F, Frérot B, Pélozuelo L, Genestier G et al. (2005) Genetic isolation between two sympatric host plant races of the European corn borer, Ostrinia nubilalis Hubner. II: assortative mating and host-plant preferences for oviposition. Heredity 94: 264-270.

Bontemps A, Bourguet D, Pélozuelo L, Bethenod MT, Ponsard S (2004). Managing evolution of Bacillus thuringiensis resistance in natural populations of the European corn borer, Ostrinia nubilalis: host plant, host race and pherotype of adult males at aggregation sites. Proc $R$ Soc Biol Sci 271: 2179-2185.

Bourguet D, Bethenod MT, Pasteur N, Viard F (2000). Gene flow in the European corn borer Ostrinia nubilalis: implications for the sustainability of transgenic insecticidal maize. Proc R Soc Biol Sci 267: 117-122.

Broman KW, Sen S, Owens SE, Manichaikul A, Southard-Smith EM, Churchill GA (2006). The $X$ chromosome in quantitative trait locus mapping. Genetics 174 2151-2158.

Broman KW, Wu H, Sen S, Churchill GA (2003). R/qtl: QTL mapping in experimental crosses. Bioinformatics 19: 889-890.

Calcagno V, Thomas Y, Bourguet D (2007). Sympatric host races of the European corn borer: adaptation to host plants and hybrid performance. J Evol Biol 20 : $1720-1729$.

Cardé RT, Kochansky J, Stimmel JF, Wheeler AG, Roelofs WL (1975). Sex pheromone of European corn borer (Ostrinia nubilalis) — Cis responding and trans responding males in Pennsylvania. Environ Entomol 4: 413-414.

Churchill GA, Doerge RW (1994). Empirical threshold values for quantitative trait mapping. Genetics 138: 963-971.

Coyne JA, Orr HA (1998). The evolutionary genetics of speciation. Philos Trans R Soc Lond Biol Sci 353: 287-305.

Coyne JA, Orr HA (2004). Speciation, Sinauer Associates, Sunderland, MA

Dempster AP, Laird NM, Rubin DB (1977). Maximum Likelihood from incomplete data via the EM algorithm. J R Stat Soc Methodol 39: 1-38.

Dopman EB, Bogdanowicz SM, Harrison RG (2004). Genetic mapping of sexual isolation between $\mathrm{E}$ and $\mathrm{Z}$ pheromone strains of the European corn borer (Ostrinia nubilalis). Genetics 167: 301-309.

Dopman EB, Perez L, Bogdanowicz SM, Harrison RG (2005). Consequences of reproductive barriers for genealogical discordance in the European corn borer. Proc Natl Acad Sci USA 102: 14706-14711.

Drès $M$, Mallet $\mathrm{J}$ (2002). Host races in plant-feeding insects and their importance in sympatric speciation. Philos Trans $R$ Soc Lond Biol Sci 357: 471-492.

Dyer LA, Singer MS, Lill JT, Stireman JO, Gentry GL, Marquis RJ et al. (2007) Host specificity of Lepidoptera in tropical and temperate forests. Nature 448: 696-699.

Feder JL, Filchak KE (1999). It's about time: the evidence for host plant-mediated selection in the apple maggot fly, Rhagoletis pomonella, and its implications for fitness trade-offs in phytophagous insects. Entomol Exp App/ 91: 211-225.

Feder JL, Nosil P (2010). The efficacy of divergence hitchhiking in generating genomic islands during ecological speciation. Evolution 64: 1729-1747.
Frolov AN, Bourguet D, Ponsard S (2007). Reconsidering the taxomony of several Ostrinia species in the light of reproductive isolation: a tale for Ernst Mayr. Biol J Linn Soc 91 49-72.

Gahukar RT (1975). Nouvelles techniques adoptées pour l'élevage d'Ostrinia nubilalis Hübner sur milieu artificiel. Ann Zool Ecol Anim 7: 491-498.

Glover T, Campbell M, Robbins P, Roelofs W (1990). Sex-linked control of sex pheromone behavioral responses in European corn borer moths (Ostrinia nubilalis) confirmed with Tpi marker gene. Arch Insect Biochem Physiol 15: 67-77.

Gort G, Koopman WJM, Stein A (2006). Fragment length distributions and collision probabilities for AFLP markers. Biometrics 62: 1107-1115.

Guthrie WD, Dollinger EJ: Stetson JF (1965). Chromosome studies of the European corn borer, smartweed borer, and lotus borer (Pyralidae). Ann Entomol Soc Am 58 $100-105$

Hall MC, Willis JH (2005). Transmission ratio distortion in intraspecific hybrids of Mimulus guttatus: implications for genomic divergence. Genetics 170 375-386.

Hawthorne DJ, Via S (2001). Genetic linkage of ecological specialization and reproductive isolation in pea aphids. Nature 412: 904-907.

Heckel DG, Gahan LJ, Liu YB, Tabashnik BE (1999). Genetic mapping of resistance to Bacillus thuringiensis toxins in diamondback moth using biphasic linkage analysis. Proc Natl Acad Sci USA 96: 8373-8377.

Huang YP, Takanashi T, Hoshizaki S, Tatsuki S, Ishikawa Y (2002). Female sex pheromone polymorphism in adzuki bean borer, Ostrinia scapulalis, is similar to that in European corn borer, O. nubilalis. J Chem Ecol 28: 533-539.

Huang YP, Tatsuki S, Kim CG, Hoshizaki S, Yoshiyasu Y, Honda H et al. (1997). Identification of sex pheromone of adzuki bean borer, Ostrinia scapulalis. J Chem Ecol 23: 2791-2802.

Jiggins CD (2008). Ecological speciation in mimetic butterflies. BioScience 58: 541-548. Keller I, Seehausen $\mathrm{O}$ (2012). Thermal adaptation and ecological speciation. Mol Ecol 21 $782-799$.

Klun JA (1975). Insect sex-pheromones-intraspecific pheromonal variability of Ostrinia nubilalis, Lepidoptera, Pyralidae in North-America and Europe. Environ Entomol 4 891-894.

Kosambi DD (1944). The estimation of map distances from recombination values. Ann Eugen 12: 172-175

Lassance JM, Bogdanowicz SM, Wanner KW, Löfstedt C, Harrison RG (2011). Gene genealogies reveal differentiation at sex pheromone olfactory receptor loci in pheromone strains of the European corn borer, Ostrinia nubilalis. Evolution 65: 1583-1593.

Lassance JM, Groot AT, Lienard MA, Antony B, Borgwardt C, Andersson F et al. (2010). Allelic variation in a fatty-acyl reductase gene causes divergence in moth sex pheromones. Nature 466: 486-489.

Lassance JM, Lienard MA, Antony B, Qian S, Fujii T, Tabata J et al. (2013). Functiona consequences of sequence variation in the pheromone biosynthetic gene pgFAR for Ostrinia moths. Proc Natl Acad Sci USA 110: 3967-3972.

Lassance JM, Löfstedt C (2009). Concerted evolution of male and female display traits in the European corn borer, Ostrinia nubilalis. BMC Biol 7: 10

Leliaert F, Verbruggen $\mathrm{H}$, Wysor B, De Clerck $O$ (2009). DNA taxonomy in morphologically plastic taxa: algorithmic species delimitation in the Boodlea complex (Chlorophyta: Cladophorales). Mol Phylogenet Evol 53: 122-133.

Linn CE, Young MS, Gendle M, Glover TJ, Roelofs WL (1997). Sex pheromone blend discrimination in two races and hybrids of the European corn borer moth, Ostrinia nubilalis. Physiol Entomol 22: 212-223.

Malausa T, Bethenod MT, Bontemps A, Bourguet D, Cornuet JM, Ponsard S (2005). Assortative mating in sympatric host races of the European corn borer. Science $\mathbf{3 0 8}$ 258-260

Malausa T, Dalecky A, Ponsard S, Audiot P, Streiff R, Chaval Y et al. (2007a). Genetic structure and gene flow in French populations of two Ostrinia taxa: host races or sibling species? Mol Ecol 16: 4210-4222.

Malausa T, Leniaud L, Martin JF, Audiot P, Bourguet D, Ponsard S et al. (2007b). Molecular differentiation at nuclear loci in French host races of the European corn bore (Ostrinia nubilalis). Genetics 176: 2343-2355.

Malausa T, Pélissié B, Piveteau V, Pelissier C, Bourguet D, Ponsard S (2008). Differences in oviposition behaviour of two sympatric sibling species of the genus Ostrinia. Bull Entomol Res 98: 193-201.

Martel C, Réjasse A, Rousset F, Bethenod MT, Bourguet D (2003). Host-plant-associated genetic differentiation in Northern French populations of the European corn borer. Heredity 90: 141-149.

Matsubayashi KW, Ohshima I, Nosil P (2010). Ecological speciation in phytophagous insects. Entomol Exp App/ 134: 1-27.

Midamegbe A, Vitalis R, Malausa T, Delava E, Cros-Arteil S, Streiff R (2011). Scanning the European corn borer (Ostrinia spp.) genome for adaptive divergence between hostaffiliated sibling species. Mol Ecol 20: 1414-1430

Orr HA, Irving S (2005). Segregation distortion in hybrids between the Bogota and USA subspecies of Drosophila pseudoobscura. Genetics 169: 671-682.

Pélozuelo L, Malosse C, Genestier G, Guenego H, Frérot B (2004). Host-plant specialization in pheromone strains of the European corn borer Ostrinia nubilalis in France. $J$ Chem Ecol 30: 335-352.

Pélozuelo L, Meusnier S, Audiot P, Bourguet D, Ponsard S (2007). Assortative mating between European corn borer pheromone races: beyond assortative meeting. PLoS One 2. 5555

Phadnis N, Orr HA (2009). A single gene causes both male sterility and segregation distortion in Drosophila hybrids. Science 323: 376-379. 
Pratt GF (1994). Evolution of Euphilotes (Lepidoptera: Lycaenidae) by seasonal and host shifts. Biol J Linn Soc 51: 387-416.

Roelofs W, Glover T, Tang X-H, Sreng I, Robbins P, Eckenrode C et al. (1987). Sex pheromone production and perception in European corn borer moths is determined by both autosomal and sex-linked genes. Proc Natl Acad Sci USA 84: 7585-7589.

Rogers SM, Bernatchez L (2006). The genetic basis of intrinsic and extrinsic post-zygotic reproductive isolation jointly promoting speciation in the lake whitefish species complex (Coregonus clupeaformis). J Evol Biol 19: 1979-1994.

Royer L, McNeil JN (1992). Evidence of a male sex pheromone in the European corn borer, Ostrinia nubilalis (Hübner) (Lepidoptera, Pyralidae). Canad Entomol 124: 113-116.

Rundle HD, Nosil P (2005). Ecological speciation. Ecol Letts 8: 336-352.

Sahara K, Yoshido A, Traut W (2012). Sex chromosome evolution in moths and butterflies. Chromosome Res 20: 83-94.

Servedio MR, Doorn GSV, Kopp M, Frame AM, Nosil P (2011). Magic traits in speciation: 'magic' but not rare? Trends Ecol Evol 26: 389-397.

Solignac M, Vautrin D, Baudry E, Mougel F, Loiseau A, Cornuet JM (2004). A microsatellite-based linkage map of the Honeybee Apis mellifera L. Genetics 167: 253-262.

Speybroeck J, Beukema W, Crochet PA (2010). A tentative species list of the European herpetofauna (Amphibia and Reptilia)—an update. Zootaxa 2492: 1-27.
Stam P (1993). Construction of integrated genetic linkage maps by means of a new computer package-JOINMAP. Plant J 3: 739-744.

Takanashi T, Huang YP, Takahasi KR, Hoshizaki S, Tatsuki S, Ishikawa Y (2005). Genetic analysis and population survey of sex pheromone variation in the Adzuki bean borer moth, Ostrinia scapulalis. Biol J Linn Soc 84: 143-160.

Tatsuta H, Takano-Shimizu T (2009). High genetic differentiation between an African and a non-African strain of Drosophila simulans revealed by segregation distortion and reduced crossover frequency. Genetica 137: 165-171.

Tenaillon MI, Charcosset A (2011). A European perspective on maize history. Comp Rend Biol 334: 221-228.

Thomas Y, Bethenod MT, Pélozuelo L, Frérot B, Bourguet D (2003). Genetic isolation between two sympatric host-plant races of the European corn borer, Ostrinia nubilalis Hübner. I. sex pheromone, moth emergence timing, and parasitism. Evolution 57: 261-273.

Winter CB, Porter AH (2009). AFLP linkage map of hybridizing swallowtail butterflies, Papilio glaucus and Papilio canadensis. J Hered 101: 83-90.

Wood TK, Keese MC (1990). Host-plant induced assortative mating in Enchenopa treehoppers. Evolution 44: 619-628.

Yasukochi Y, Miura N, Nakano R, Sahara K, Ishikawa Y (2011). Sex-linked pheromone receptor genes of the European corn borer, Ostrinia nubilalis, are in tandem arrays. PLoS One 6: e18843.

Supplementary Information accompanies this paper on Heredity website (http://www.nature.com/hdy) 